\title{
Meta
}

Journal des traducteurs

Translators' Journal

\section{PASEWAlK, Silke, NeIDlinger, Dieter et Loogus, Terje, dir. (20I4) : Interkulturalität und (literarisches) Übersetzen. Tülbingen : Stauffenburg, 334 p.}

\section{Jürgen Heizmann}

Volume 61, numéro hors-série, 2016

URI : https://id.erudit.org/iderudit/1038694ar

DOI : https://doi.org/10.7202/1038694ar

Aller au sommaire du numéro

Éditeur(s)

Les Presses de l’Université de Montréal

ISSN

0026-0452 (imprimé)

1492-1421 (numérique)

Découvrir la revue

Citer ce compte rendu

Heizmann, J. (2016). Compte rendu de [PASEWALK, Silke, NEIDLINGER, Dieter et LOoGUs, Terje, dir. (20I4) : Interkulturalität und (literarisches) Übersetzen.

Tübingen : Stauffenburg, 334 p.] Meta, 61, 179-180.

https://doi.org/10.7202/1038694ar

Ce document est protégé par la loi sur le droit d'auteur. L'utilisation des services d’Érudit (y compris la reproduction) est assujettie à sa politique d'utilisation que vous pouvez consulter en ligne.

https://apropos.erudit.org/fr/usagers/politique-dutilisation/
Cet article est diffusé et préservé par Érudit.

Érudit est un consortium interuniversitaire sans but lucratif composé de l’Université de Montréal, l'Université Laval et l'Université du Québec à Montréal. Il a pour mission la promotion et la valorisation de la recherche. https://www.erudit.org/fr/ 
Pasewalk, Silke, Neidlinger, Dieter et Loogus, Terje, dir. (2014): Interkulturalität und (literarisches) Übersetzen. Tübingen: Stauffenburg, $334 \mathrm{p}$.

Une scène du film Lost in Translation de Sophia Coppola (États-Unis 2003) illustre les problèmes émanant de la collision entre deux langues et deux cultures. L'acteur Bob Harris (interprété par Bill Murray) se trouve dans un studio de Tokyo pour y tourner une publicité. L'interprète japonaise lui transmet les instructions du réalisateur japonais, mais l'original et la traduction diffèrent énormément: l'interprète condense le monologue du réalisateur en une demi-phrase, au grand étonnement d'un Bob Harris perplexe. Cette scène résume aussi les problématiques de la traduction: compréhension et incompréhension, rencontre de deux cultures (un Américain au Japon), divergences entre langues et cultures, adéquation d'une traduction, perte ou gain d'une traduction. Dans les théories récentes de traductologie, la culture et le transfert entre les cultures ont gagné une importance significative, au point que les cultural studies, à la suite du tournant culturel pris par les études postcoloniales (Homi Bhaba et Gayatri Spivak), ont définitivement remplacé la linguistique comme discipline majeure de la traductologie. Pour résumer très brièvement ce phénomène: aujourd'hui, on s'accorde sur le fait que l'on ne traduit pas des langues, mais des cultures.

Ce recueil, fruit d'un congrès international qui s'est tenu du 30 septembre au 2 octobre 2011 à Tartu en Estonie et qui rassemblait des germanistes, des traductologues et des traducteurs, s'inscrit dans cet ordre d'idées. Cet ouvrage a pour prémisse que le paradigme de l'interculturalité est bien établi dans les sciences littéraires et dans la traductologie, mais que, malgré tout, les deux disciplines n'échangent guère leur point de vue sur les possibilités et les limites de ce paradigme. Ni la traduction ni la littérature ne peuvent désormais être abordées en dehors de la culture, telle est l'idée principale de l'ouvrage divisé en cinq chapitres: 1. Conceptions de l'interculturalité et de la culture dans les sciences littéraires et la traductologie; 2. Littérature et traduction; 3 . Littérature et interculturalité; 4 . Traduction comme transfert entre cultures; 5 . Traduction et allemand comme langue étrangère.

Les articles du premier chapitre visent à clarifier les concepts de culture, d'interculturalité et detransculturalité. Le dernier concept, défendu notamment par le philosophe Wolfgang Welsch dans l'espace germanophone, ne définit plus les cultures comme entités séparées, mais comme point de départ d'un modèle d'interpénétration et d'hybridité de chaque culture. Dans leur contribution, Corinna Albrecht, Terje Loogus et Christine Nord insistent chacune sur le fait que les conceptions de l'interculturalité peuvent bel et bien coexister avec la transculturalité. Christine Nord admet que, dans l'ère de la mondialisation et d'un monde interconnecté, on ne trouve plus de groupes homogènes; l'auteure souligne que chaque traducteur et interprète a cependant conscience que des malentendus créés par son propre contexte culturel sont toujours possibles, ce qui ne serait pas le cas si chaque individu possédait une identité transculturelle comme Welsch le prétend. Notre perception et notre évaluation des situations sont guidées par notre formation socioculturelle. Selon Albrecht, la confrontation avec l'étranger ouvre les yeux sur le fait que notre mode de perception et d'interprétation est toujours associé à une culture. En conséquence, l'interculturalité est un processus de conscience et de cognition autoréflexif qui aide à surmonter l'ethnocentrisme en partant d'une pluralité culturelle qui inclut la perspective de l'autre. Terje Loogus, quant à elle, décrit dans une récapitulation historique comment culture est devenue le terme central de la traductologie. Un représentant important de cette orientation est le fondateur de la théorie du skopos (Skopostheorie), Hans J. Vermeer, qui a défini la culture comme la somme de toutes les normes et conventions qui règlent la coexistence et les interactions des individus au sein d'une culture. Les idées de Vermeer sont exemplaires pour la traductologie fonctionnelle allemande, l'une des écoles les plus suivies dans le secteur de la traduction spécialisée. Comme les études descriptives (Descriptive Translation Studies), l'approche fonctionnelle allemande se concentre sur la communauté culturelle et communicative pour laquelle une traduction est réalisée; les deux écoles défendent l'idée que la connaissance d'une langue ne présuppose pas la connaissance d'une culture.

L'article de Jürgen Joachimsthaler, divisé en douze chapitres, met en lumière un grand nombre d'idées pertinentes. Joachimsthaler prend comme exemple l'influence actuelle de la langue anglaise sur le lexique, la syntaxe et le style de la langue allemande pour montrer à quel point les traductions peuvent manipuler la structure d'une langue qui n'est jamais «pure». Les traductions de Shakespeare ou de Baudelaire, Rimbaud et Mallarmé ont connu une influence prédominante sur le développement de la langue allemande, car elles ont élargi le répertoire d'expressions et ont donné le jour à un nouveau style linguistique. À l'inverse, une traduction peut avoir influer sur la langue originale; l'écriture et la traduction des chansons lituaniennes par des prêtres allemands ont constitué une source importante pour le développement du Lituanien écrit et littéraire. L'image populaire 
du traducteur en tant que "passeur» n'est pas valide, selon Joachimstahler, car le traducteur ne se trouve pas entre deux rives statiques, mais plutôt dans un champ d'interaction entre différentes cultures. Dans l'acte de traduction, la conscience du traducteur agit dans les deux langues simultanément. Qui plus est, un traducteur ne traduit pas vers une langue complète, fixe, il opère avec les possibilités expressives d'une langue, tâche de «desserrer son corset» pour citer ici l'expression célèbre de Karl Kraus à propos de Heinrich Heine et son traitement de l'allemand. Cette créativité du traducteur est particulièrement palpable dans le cas des langues artificielles tels l'esperanto, l'interlingua ou bien le klingon, la langue crée par le linguiste Marc Okrand pour la série Star Trek, vers laquelle on a déjà traduit Hamlet, le Tao-te-King et l'Épopée de Gilgamesh. Dans ce sens, on peut dire qu'une traduction crée de nouveaux espaces linguistiques pour de nouvelles communautés.

Dans son article, Maris Saagpaak examine les rapports culturels entre l'Estonie et l'Allemagne en se basant sur la littérature baltico-allemande traduite vers l'estonien dans l'ère postsoviétique. Selon le répertoire de l'auteure, quarante-neuf titres ont été traduits entre 1990 et 2009. L'histoire culturelle baltico-allemande, dit Saagpaak, s'est intégrée à l'histoire culturelle estonienne; que les textes des auteurs baltico-allemands tels Hermann von Keyserling et Georg Julius von Schultz-Bertram soient publiés dans la collection la plus respectée en Estonie, Eesti mõttelugu, en donnerait la preuve. Pour la réception de cette littérature, la valeur historique serait plus importante que les aspects esthétiques, car elle servirait, de prime abord, comme source d'information sur une époque du passé. Selon Saagpaak, la littérature baltico-allemande est cependant, malgré la bonne qualité des traductions, trop étrangère aux lecteurs estoniens, raison pour laquelle elle ne peut se maintenir sur le marché littéraire.

La germaniste et traductologue belge Céline Letawe examine le rapport de l'auteur Günter Grass avec ses traducteurs. Insatisfait de plusieurs traductions imprécises et, selon lui, mauvaises de ses œuvres, Grass ne faisait plus confiance à ses traducteurs. Il organisa des séminaires pour discuter avec eux des difficultés de ses textes, comme des noms de repas ou de clubs sportifs, l'ironie, des passages dialectaux, des expressions idiomatiques, des jeux de mots ou des particularités de style. Le premier de ces séminaires s'est tenu entre le 29 janvier et le 4 février 1978, le dernier, du 14 au 16 mars 2011. D’après les comptes rendus issus de ces rencontres, Letawe présente les différentes stratégies des traducteurs pour surmonter les difficultés du transfert culturel. Grass, et c'est là un exemple intéressant, explique la signification de l'expression idiomatique Pferde stehlen (être avec quelqu'un contre vents et marées) avec laquelle il joue dans son roman Der Butt. Le traducteur anglais a trouvé une autre image, courante pour le lecteur anglophone: "You could go through fire and water with Lena. [...] But I don't want to go through fire and water.» Le traducteur néerlandais, quant à lui, a repris la solution proposée par Grass : «Met Lena kon je bergen verzetten. [...] Maar van mij hoeven de bergen niet verzet. (Avec Lena, je peux déplacer des montagnes. [...] Mais, pour moi, il n’est pas nécessaire de déplacer des montagnes. [traduction de Jürgen Heizmann]) Le traducteur français (qui n’a pas participé au séminaire) a opté pour la traduction littérale, "voler des chevaux avec elle»(p.134), qui est, cependant, presque impossible à comprendre pour un lecteur francophone, car elle ne correspond à aucune expression idiomatique française. Les exemples discutés par Letawe montrent de façon lucide que le traducteur est un médiateur non seulement pour les langues, mais aussi pour les cultures et que sa traduction joue un rôle clé dans la perception de l'altérité d'une culture.

On pourrait regretter que Norbert $\mathrm{Mec}$ klenburg, grand seigneur de l'interculturalité dans les études littéraires et auteur de livres fondamentaux sur le sujet, ne propose qu'une rétrospective personnelle sur le développement de cette méthode en philologie. Quant à la contribution de Gertrud Maria Rösch, qui se penche sur les romans à clef allemands contemporains, un genre littéraire souvent sous-estimé, on ne peut guère cacher l'impression que l'auteure, qui a écrit plusieurs œuvres et même édité une encyclopédie à ce sujet, a repris des idées de ses anciennes publications et a tenté de les adapter au thème du recueil au moyen d'une unique métaphore: le roman à clef serait la traduction de la réalité en fiction. Comment un traducteur pourrait-il transférer les informations clandestines d'un roman à clef? La méthode par laquelle ces informations deviendraient aisément saisissables pour un lecteur ne partageant pas le même milieu culturel pourrait éventuellement ouvrir un nouveau champ de recherche en littérature comparée et en traductologie.

Somme toute, ce recueil offre plusieurs perspectives théoriques et pragmatiques sur les tâches et les responsabilités du traducteur ainsi que sur le lien entre langue, littérature et culture. Le chercheur peut y trouver maintes avenues pour ses propres recherches.

JÜRgEN HeIZMANN Université de Montréal, Montréal, Canada 